\title{
Hereditary fructose intolerance
}

INSERM

\section{Source}

INSERM. (1999). Orphanet: an online rare disease and orphan drug data base. Hereditary fructose intolerance. ORPHA:469

Hereditary fructose intolerance $(\mathrm{HFI})$ is an autosomal recessive disorder of fructose metabolism (see this term), resulting from a deficiency of hepatic fructose-1-phosphate aldolase activity and leading to gastrointestinal disorders and postprandial hypoglycemia following fructose ingestion. $\mathrm{HFI}$ is a benign condition when treated, but it is lifethreatening and potentially fatal if left untreated. 